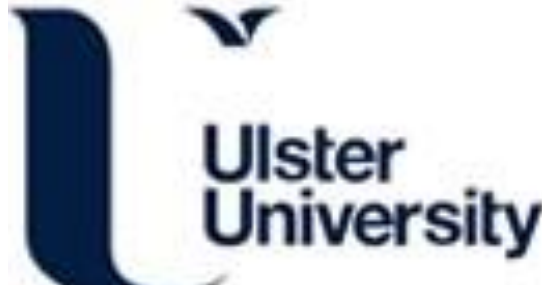

\section{Biosurfactants: a sustainable replacement for chemical surfactants?}

Marchant, R., \& Banat, I. (2012). Biosurfactants: a sustainable replacement for chemical surfactants? Biotechnology Letters, 34(9), 1597-1605.

Link to publication record in Ulster University Research Portal

\section{Published in:}

Biotechnology Letters

Publication Status:

Published (in print/issue): 01/08/2012

\section{Document Version}

Publisher's PDF, also known as Version of record

\section{General rights}

Copyright for the publications made accessible via Ulster University's Research Portal is retained by the author(s) and / or other copyright owners and it is a condition of accessing these publications that users recognise and abide by the legal requirements associated with these rights.

\section{Take down policy}

The Research Portal is Ulster University's institutional repository that provides access to Ulster's research outputs. Every effort has been made to ensure that content in the Research Portal does not infringe any person's rights, or applicable UK laws. If you discover content in the Research Portal that you believe breaches copyright or violates any law, please contact pure-support@ulster.ac.uk. 


\section{Biosurfactants: a sustainable replacement for chemical surfactants?}

\section{Roger Marchant \& Ibrahim M. Banat}

\section{Biotechnology Letters}

ISSN 0141-5492

Biotechnol Lett

DOI 10.1007/s10529-012-0956-x

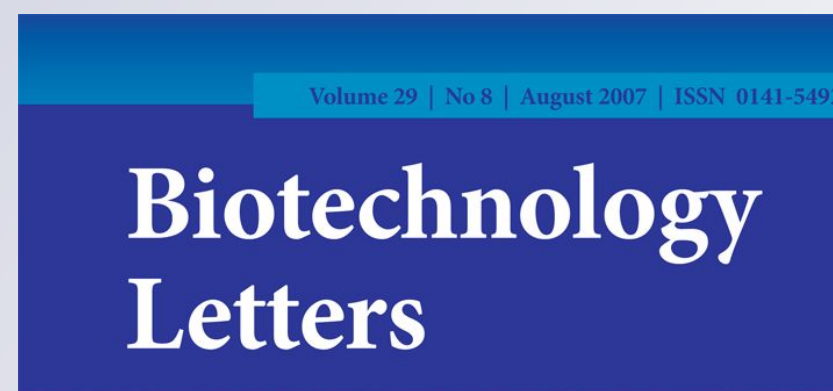

A monthly journal for the rapid communication of results and developments in all aspects of biotechnology

Executive Editors

Colin Ratledge, Editor in Chief (University of Hull, UK)

David Archer (University of Nottingham, UK)

Chris J. Hewitt (University of Loughborough, UK)

Roger Marchant (University of Ulster, Northern Ireland, UK)

Danny Rangasamy (Australian National University, Australia)

Mark Smales (University of Kent, UK)

Farlan Veraitch (University College London, UK)

Rob Verpoorte (Leiden University, NL)

Springer

包 Springer 
Your article is protected by copyright and all rights are held exclusively by Springer Science+Business Media B.V.. This e-offprint is for personal use only and shall not be selfarchived in electronic repositories. If you wish to self-archive your work, please use the accepted author's version for posting to your own website or your institution's repository. You may further deposit the accepted author's version on a funder's repository at a funder's request, provided it is not made publicly available until 12 months after publication. 


\title{
Biosurfactants: a sustainable replacement for chemical surfactants?
}

\author{
Roger Marchant • Ibrahim M. Banat
}

Received: 21 March 2012/ Accepted: 4 May 2012

(C) Springer Science+Business Media B.V. 2012

\begin{abstract}
Glycolipid biosurfactants produced by bacteria and yeasts provide significant opportunities to replace chemical surfactants with sustainable biologically produced alternatives in bulk commercial products such as laundry detergents and surface cleaners. Sophorolipids are already available in sufficient yield to make their use feasible while rhamnolipids and mannosylerythritol lipids require further development. The ability to tailor the biosurfactant produced to the specific needs of the product formulation will be an important future step.
\end{abstract}

Keywords Biofilm - Cleaning products . Glycolipid biosurfactants - Mannosylerythritol lipids · Oil spills · Rhamnolipids · Sophorolipids ·

Wound healing

\section{Introduction}

Biosurfactants are produced mainly, but not exclusively, by microorganisms both bacteria and fungi (including yeasts), and have surface active properties. These surface interactions are mediated by the amphiphilic nature of the molecules, which have hydrophilic

R. Marchant $(\bowtie) \cdot$ I. M. Banat

School of Biomedical Sciences, University of Ulster,

Coleraine, County Londonderry, Northern Ireland

BT521SA, UK

e-mail: r.marchant@ulster.ac.uk and hydrophobic regions, allowing them to act as surfactants at the interfaces between aqueous and nonaqueous components in a complex system and at the liquid gas interface. Some of these molecules are effective emulsifiers while others reduce surface tension at oil water interfaces. The differences in solubility, surface and interface reducing capability, critical micelle concentration together with detergency, wetting and foaming will make a given surfactant more or less suitable for a particular application (Myers 2006).

Similar properties are displayed by chemicallysynthesised surfactants which come from petrochemical or oleochemical sources (Desai and Banat 1997) and these compounds have been extensively developed for large scale industrial applications, particularly in the area of cleaning products such as detergents and surface cleaners. The vigorous current movement for industrial sustainability has stimulated active interest in biosurfactants as possible replacements for at least some of these chemical surfactants. In addition to biosurfactants being produced from renewable feedstocks, they also have characteristics that fall under the overused and inaccurate term 'environmentally friendly.' The fact that they can be readily biodegraded means that they are significantly less damaging to the environment than the more recalcitrant chemical surfactants and their ability to withstand high temperatures and to tolerate high salt concentrations makes them attractive components for many industrial products (Banat et al. 2010). This 
short review will concentrate on a specific group of biosurfactants that fall in the glycolipid category and which have become the target for industrial attention over the last few years. In particular we will look at the sophorolipids, the rhamnolipids and the mannosylerythritol lipids (MELS) and examine the current situation and future prospects for each focussing on the areas of research that are underway and those that are needed for further development and exploitation to take place.

The structure of glycolipid biosurfactants

Microbially-produced biosurfactants fall into two major categories, low molecular weight (LMW) and high molecular weight (HMW) (Ron and Rosenberg 2001; Smyth et al. 2010b, c). In this review we will only consider the LMW biosurfactants and, in particular, the glycolipid members of this group rather than the lipopeptides. The glycolipid biosurfactants comprise a hydrophilic carbohydrate section and a hydrophobic fatty acid chain. The sugar at the hydrophilic end is sophorose in the sophorolipids, rhamnose in the rhamnolipids and mannose and erythritol in MELS. There are a few other glycolipid biosurfactants e.g. trehalose lipids and cellobiose lipids but they have so far attracted less interest.

The sophorolipids are produced by yeasts of the genus Candida, particularly C. bombicola and C. apicola, and are produced in mixtures comprising usually 8 major and up to 15 minor components (Table 1) (van Bogaert et al. 2007). Sophorose, a 1,2disaccharide of glucose, forms the hydrophilic head of the molecule that may or may not be acetylated with one or two acetyl groups. The fatty acid chain typically has 16 or 18 carbon atoms with different degrees of saturation (none, one or two double bonds). Sophorolipid molecules exist either in the acidic or lactonic form; in the latter, the carboxylic end of the fatty acid is esterified at the $4^{\prime \prime}-$, or less frequently at the $6^{\prime}$ - or $6^{\prime \prime}$-position, of the sophorose unit. The possible variants make the sophorolipid mixture produced by Candida species very complex, although lactonic sophorolipid with 17-hydroxy-octadecanoic acid is reported to be the predominant congener (van Bogaert et al. 2007).

Some control over the sophorolipid structures produced can be achieved through strain selection and changes to the culture conditions, however it is not possible to alter the functional backbone by feeding sugars other than glucose (Klekner et al. 1991) or fatty acids with a shorter or longer carbon chain (Van Bogaert et al. 2011) (Fig. 1).

Rhamnolipids are produced most abundantly by the bacterium Pseudomonas aeruginosa, although other reports have indicated that rhamnolipid biosurfactants are also produced by Pseudomonas chlororaphis strain NRRL B-30761 which synthesises only monorhamnolipids using $\mathrm{C}_{10}$ and $\mathrm{C}_{12: 1}$ fatty acyl chains (Gunther et al. 2005) and Burkholderia thailandensis (Dubeau et al. 2009) which only produces di-rhamnolipid with $\beta$-hydroxy-tetradecanoic acid $\left(\mathrm{C}_{14}\right)$ and Burkholderia pseudomallei (Haussler et al. 1998) which is similar to B. thailandensis. Significantly, $P$. chlororaphis and $B$. thailandensis are have no known human pathogenicity, which would make them
Table 1 Representative chemical composition of sophorolipid mixture produced by $C$. apicola ATCC 96134 in a bioreactor fermentation with oleic acid as the major carbon source based on HPLC data (unpublished data)

\begin{tabular}{llllc}
\hline No. & Possible structure & RT $(\mathrm{min})$ & $(\mathrm{m} / \mathrm{z})$ & Abundance $(\%)$ \\
\hline $\mathbf{1}$ & Acidic, C18:1 & $\mathbf{6 . 9 3}$ & $\mathbf{6 2 1}$ & $\mathbf{6 . 5}$ \\
2 & Acidic, C18:1, 1Ac & 7.93 & 663 & 4.9 \\
3 & Acidic, C18:2, 2Ac & 9.84 & 703 & 2.8 \\
$\mathbf{4}$ & Acidic, C18:1, 2Ac & $\mathbf{1 2 . 1 3}$ & $\mathbf{7 0 5}$ & $\mathbf{4 8 . 1}$ \\
5 & Acidic, C18:0, 2Ac & 16.54 & 707 & 2.8 \\
6 & Lactonic, C18:1, 1Ac & 24.69 & 645 & 3.06 \\
7 & Lactonic, C18:2, 2Ac & 36.45 & 685 & 2.7 \\
8 & Lactonic, C18:2, 2Ac & 39.25 & 685 & 2.2 \\
9 & Lactonic, C16:0, 2Ac & 44.21 & 661 & 1.1 \\
10 & Lactonic, C18:1, 2Ac & 47.73 & 687 & 4.6 \\
$\mathbf{1 1}$ & Lactonic, C18:1, 2Ac & $\mathbf{4 9 . 6 8}$ & $\mathbf{6 8 7}$ & $\mathbf{1 0 . 0}$ \\
12 & Lactonic, C18:0, 2Ac & 67.92 & 689 & 4.1 \\
\hline
\end{tabular}


Fig. 1 Structures of biosurfactants: monorhamnolipid (a) and di-rhamnolipid (b) from $P$. aeruginosa in which one and two molecules of rhamnose are linked to two $\beta$-hydroxy-decanoic acid chains; sophorolipid in open chain (c) and lactonic (d) form from C. bombicola in which one molecule of sophorose is linked to a chain of hydroxyl-fatty acid ( $n=15, \mathrm{R}^{1}$ and $\mathrm{R}^{2}=\mathrm{H}$ and/or $\mathrm{COCH}_{3}$ (a)

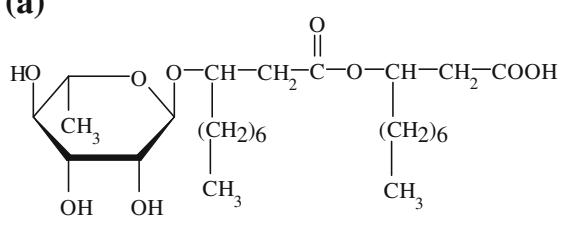

(b)

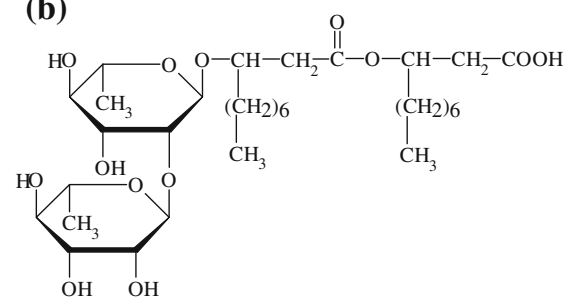

(d)

(c)

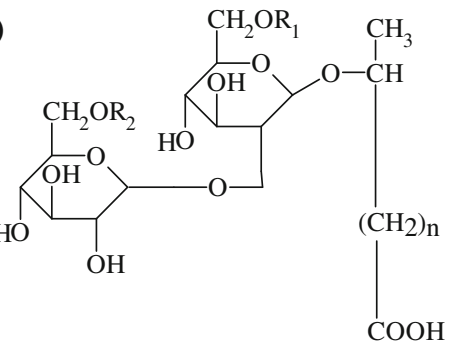

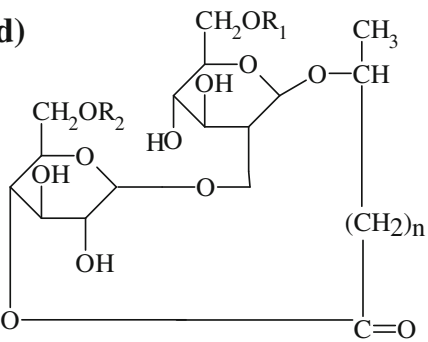

Table 2 Representative chemical composition of rhamnolipid mixture produced by $P$. aeruginosa ST5 in a bioreactor fermentation with glycerol as the major carbon source based on HPLC data (unpublished data)

\begin{tabular}{llllc}
\hline No. & Molecular congener & $(\mathrm{m} / \mathrm{z})$ & $\mathrm{RT}(\mathrm{min})$ & Abundance $(\%)$ \\
\hline 1 & Rha-C8-C10/Rha-C10-C8 & 475 & 12.80 & 5.00 \\
$\mathbf{2}$ & Rha-C10-C10 & $\mathbf{5 0 3}$ & $\mathbf{2 2 . 2 5}$ & $\mathbf{3 4 . 0}$ \\
3 & Rha-C10-C12:1/Rha-C12:1-C10 & 529 & 28.24 & 2.2 \\
4 & Rha-C10-C12/Rha-C12-C10 & 531 & 35.89 & 2.9 \\
5 & Rha-Rha-C8-C10/ & 621 & 9.01 & 6.1 \\
$\mathbf{6}$ & Rha-Rha-C10-C8 & & & \\
7 & Rha-Rha-C10-C10 & $\mathbf{6 4 9}$ & $\mathbf{1 5 . 9 5}$ & $\mathbf{4 2 . 2}$ \\
8 & Rha-Rha-C10-C12:1/ & 675 & 24.60 & 2.5 \\
8 & Rha-Rha-C12:1-C10 & & & \\
& Rha-Rha-C10-C12/ & 677 & 25.35 & 6.5 \\
\hline
\end{tabular}

attractive organisms to use for large-scale fermentation production of rhamnolipids. [Published reports of rhamnolipid production by Pseudomonas fluorescens (Vasileva-Tonkova et al. 2006, Stoimenova et al. 2009), however, could not be verified by us.] P. aeruginosa produces two types of rhamnolipid: the monoand di- forms which have one or two molecules of rhamnose, respectively, attached to $\beta$-hydroxy-decanoic acid chains (Soberón-Chávez et al. 2005). Although a range of different alkyl chain lengths occur the $\mathrm{C}_{10} \mathrm{C}_{10}$ configuration predominates and the quantities of other minor congeners only vary slightly with substrate and culture conditions (Table 2) (Perfumo et al. 2006).

Since the synthetic pathway proceeds through mono-rhamnolipid to di-rhamnolipid by the addition of a molecule of rhamnose by a specific rhamnosyl transferase, opportunities to manipulate the proportions of the two main congeners by manipulating growth conditions are limited.

MELs are produced by basidiomycetous yeasts of the genus Pseudozyma ( $P$. rugulosa, $P$. aphidis and $P$. antarctica) and by species of the fungus Ustilago (Arutchelvi et al. 2008). MELs form the main component of the Pseudozyma biosurfactants but are only a minor component of that produced by Ustilago. MELs have four major structural groups comprising 4- $O-\beta$-Dmannopyranosyl-D-erythritol connected to two medium length chains of fatty acyl esters (Fig. 2) (Fukuoka et al. 2007). As with the other microbial biosurfactants, Pseudozyma yeasts produce a mixture of congeners rather than a single predominant molecule. The 


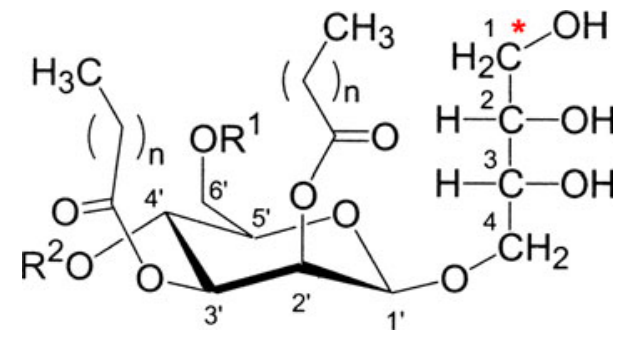

Fig. 2 Structure of MELS MEL-A: $R^{1}=R^{2}=A c$ MEL-B: $\mathrm{R}^{1}=\mathrm{Ac}, \mathrm{R}^{2}=\mathrm{H}$ : MEL-C $\mathrm{R}^{1}=\mathrm{H}, \mathrm{R}^{2}=\mathrm{Ac}$ fatty acid chain length $n=6-10^{*}$ indicates point of attachment for a further fatty acid chain $(n=12-16)$ with a terminal acyl group in the tri-acylated MEL (Adapted from Fukuoka et al. (2007))

naturally-produced MELS are acylated structures with either two acyl groups MEL-A, MEL-B and MEL-C or three acyl groups, although Fukuoka et al. (2007) have also reported the formation of a mono-acylated MEL produced by Pseudozyma antarctica grown on glucose. In addition to the variation induced by the level of acylation in the MELS produced, the fatty acid chains are also not of a consistent length or degree of unsaturation. Fukuoka et al. (2007) reported chain lengths from $\mathrm{C}_{6}$ to $\mathrm{C}_{16}$ in MELS with $>75 \%$ of the MEL-A in $P$. antarctica grown on soybean oil made up of $\mathrm{C}_{8}$ and $\mathrm{C}_{10}$ chain length molecules. In many of the MEL producers belonging to the genus Pseudozyma, MEL-A is the predominant product comprising $70 \%$ of the total biosurfactant produced. Unfortunately the low water solubility of MEL-A limits its potential commercial use.

\section{Efficacy for specific applications}

As we have seen, the glycolipid biosurfactants are produced by microorganisms in complex mixtures with more than one major component. If they are to be used in commercial formulations it is essential to determine whether all the components behave similarly or whether separation, purification or enrichment of one component would be desirable and cost effective. To this end, detailed investigation of the self-assembly and surface activity at the air/water interface of sophorolipids (Penfold et al. 2011; Chen et al. 2011) and rhamnolipids (Chen et al. 2010a, b) have been carried out using neutron beam scattering techniques. To carry out this work effectively surfactant molecules labelled with deuterium atoms are required, however, many microorganisms, particularly bacteria react adversely to deuterated substrates. A progressive adaptation programme can overcome the problem and, by careful use of deuterated substrates and deuterated water in the growth medium, selective labelling of different parts of the surfactant molecule can be achieved (Smyth et al. 2010a). The investigation of the behaviour of the biosurfactants alone and in combination with synthetic surfactants which are employed in current cleaning product formulations such as sodium dodecyl benzene sulfonate (LAS) has shown that the different forms produced behave differently. These varying behaviours are due to the size and structure of the molecules, for example micelle sizes are different between the mono and dirhamnolipids and aggregation of the acidic and lactonic forms of sophorolipid are not identical. The more hydrophobic lactonic form is more surface active than the acidic form, with a lower critical micellar concentration, CMC, and stronger surface adsorption. Depending on the function required for the biosurfactant in a final product formulation there will be a requirement for either a single form of the molecule to be available or for the naturally produced mixture to be manipulated to give changed ratios of components.

Opportunities to improve naturally-occurring biosurfactants

The simplest approach to achieve different ratios of biosurfactants in the mixed products is to examine different strains of the producer organism combined with different culture conditions. In the case of the rhamnolipids produced by $P$. aeruginosa, this strategy has not been successful since in a wide range of freshly isolated strains similar production patterns were observed (A. Perfumo unpublished results) and although yield can be modified significantly by changing the growth conditions the composition is relatively stable (Mata-Sandoval et al. 2001).

The other possibility is to take the mixed product and to carry out a chemical separation of the components; while this is feasible on a small scale the column chromatography techniques necessary to separate similar molecules are not economic on a large scale (Smyth et al. 2010b). The pathway for rhamnolipid formation proceeds through hydroxyl-alkanoic acid (HAA) with the subsequent addition of one rhamnose molecule to form mono rhamnolipid and thence by a further 


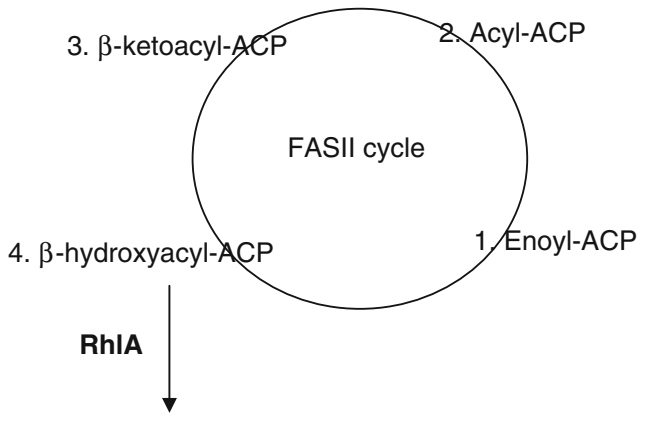

$\beta$-D-( $\beta$-D-hydroxyalkanoyloxy)alkanoic acids (HAAs)

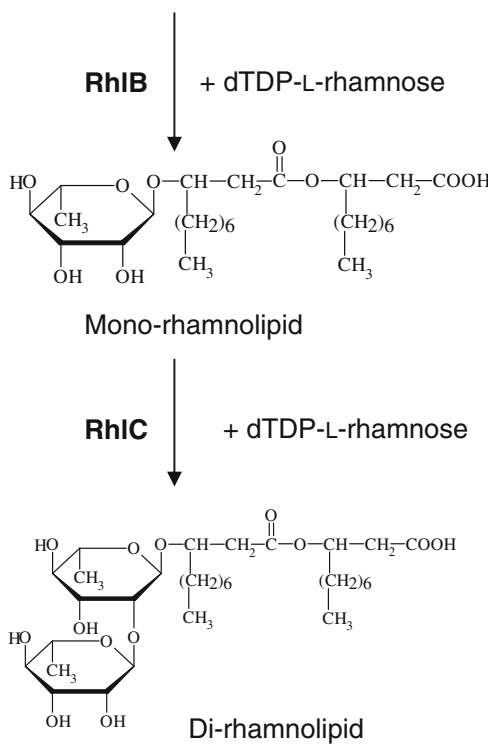

Fig. 3 Proposed pathway for the synthesis of rhamnolipids in P. aeruginosa

rhamnose addition to di-rhamnolipid (Fig. 3) (Zhu and Rock 2008).

This provides an opportunity to knock-out the second rhamnosyl transferase gene $(r h l C)$ and to produce a strain producing only mono rhamnolipid. Such a knock-out has been achieved in a study of swarming patterns, but a complete investigation of the yields of mono rhamnolipid possible have not been made (Caiazza et al. 2005), however, the kinetic characteristics of the $r h l B$ gene product may severely limit the yields of mono rhamnolipid possible. Another molecular biology approach is to clone the rhamnolipid operon, or parts of it, into a different organism. This is a potentially attractive option since the fact that $P$. aeruginosa is a class II organism is a strong disincentive for large scale fermentation applications. Once again this has been achieved (Ochsner et al. 1994) but the resulting yields of rhamnolipid were very low, as might be expected since production of the rhamnolipid will depend on the metabolic flux of the precursors within the recipient strain. Currently interest is centered on investigation of the few other known non-pathogenic rhamnolipid producing bacteria one of which apparently produces only mono rhamnolipid (P. chlororaphis, Gunther et al. 2005) and another predominantly di-rhamnolipid although with longer acyl chains than $P$. aeruginosa (Burkholderia thailandensis, Dubeau et al. 2009). It is already clear that the presence of $\mathrm{C}_{14}$ chain length acyl moieties in the di-rhamnolipid of $B$. thailandensis produces a surfactant that does not reduce the surface tension of the growth medium in the dramatic way that occurs with $P$. aeruginosa (unpublished results) indicating that this product may have very different applications in commercial formulations.

Sophorolipids have already found applications in domestic products, particularly in Japan and Korea. The rapid uptake of these biosurfactants into mature product areas has been driven to a large extent by the fact that high yields of sophorolipids $(>100 \mathrm{~g} / \mathrm{l})$ are relatively easy to achieve in culture and this, in turn, makes purification and downstream processing economically attractive. However, the low cost and ease of production does not necessarily mean that these biosurfactants are the most effective molecules available and there are large behaviour differences between the acidic and lactonic forms of the molecules (Penfold et al. 2011). The complexity of the mixtures of molecules produced by the Candida species coupled with the chemical similarity of the products again means that separation and purification methods on an industrial scale are not economically attractive. This has led to an interest in tailoring the sophorolipids produced specifically for industrial needs through genetic manipulation. The first important steps in this pathway have already been completed and work is ongoing to expand the extent and application of this work. Recently, new-to-nature sophorolipids have been produced by genetic manipulation of Candida bombicola (Saerens et al. 2011; Van Bogaert et al. 2009). This new approach should allow changes to be introduced into both the carbohydrate head and the lipid tail of the sophorolipids, including changes to the chain length and degree of saturation of the tail and the degree of acetylation of the carbohydrate. Control over the formation of the lactonic form of the surfactants 
should also be achievable. Whether after such genetic manipulation strains can be produced that will give commercially viable yields remains to be determined.

The gene cluster responsible for the synthesis of MELS in Ustilago maydis under conditions of nitrogen limitation have been described by Hewald et al. (2006). The MEL biosynthesis gene cluster comprises the mat 1 acetyltransferase gene, the $m m f l$ gene, which specifies a member of the major facilitator family, macl and mac2, encoding putative acyltransferases, and the glycosyltransferase gene emtl. Deletion of the mat 1 gene resulted in the production of completely deacylated MELS. This again offers the opportunity to produce a modified product through genetic manipulation.

A different approach to modifying biosurfactants has recently been reported by Fukuoka et al. (2011). These workers took a naturally produced acylated MEL and removed the acyl groups through a lipasecatalysed hydrolysis, producing a non-acylated product which they designated MEL-D. They were able to show that the non-acylated form of MEL had a higher critical aggregation concentration but retained an excellent surface tension lowering capacity. These results suggest that the new MEL-D may have applications in fields where a lamellar-forming glycolipid is required.

\section{Cost and production}

In all potential commercial applications cost of production is critical in determining whether a new compound can be incorporated into a formulation. The initial step is to determine whether the component, in this case a biosurfactant, has the required characteristics to replace some or all of the existing chemical surfactants. This work has been carried out and biosurfactants have been identified as potentially useful sustainable ingredients for a number of commercial products. The next step is to determine whether the biosurfactant can be produced at a price which will make it competitive with existing chemical surfactants. Production costs for biosurfactants will depend on the cost of fermentation feedstock used (Makkar et al. 2011), the yield in the fermentation broth and the cost of downstream processing and the interaction between each of these factors. For example the downstream processing may be made more difficult and costly if an oily substrate is used rather than glycerol.
At the present time sophorolipids can be produced at a price that allows their use in some commercial formulations. This is mainly because relatively long fed batch fermentations using resting cells can be used with high oleic acid substrate levels to give very high yields. The use of well aerated bioreactors has been shown to produce higher levels of the lactonic form of the sophorolipids (Casas and Garcia-Ochoa 1999; Guilmanov et al. 2002) a situation which is probably enhanced by the long fermentation time since the lactonisation step is the last in the synthetic pathway (Davila et al. 1997). The possible use of glycerol as a feedstock, a cheap and plentiful by-product derived from the production of biodiesel from glycerides, may make future production even cheaper. The high yield of sophorolipids in Candida is possible since the synthetic pathway continues to operate in non-growing cells.

The production of rhamnolipids by $P$. aeruginosa is in sharp contrast to the production of sophorolipids. In the majority of strains maximum production is around $10 \mathrm{~g} / \mathrm{l}$ in a batch bioreactor system, although there have been reports of much higher yields of around $100 \mathrm{~g} / \mathrm{l}$ from hyperproducer strains (Lang and Wullbrandt 1999). Oil-containing agricultural by-products and wastes can be used as feedstocks for rhamnolipid production but the unused residues make downstream processing far more difficult. Glycerol does, however, provide a possible satisfactory feedstock for rhamnolipids. The major obstacle to obtaining high yields of rhamnolipid from $P$. aeruginosa is that the synthetic pathway is part of the quorum sensing system and is under tight genetic regulation. Recent investigations in out laboratory (unpublished results) using qRT PCR have shown that the rhamnosyl transferase coded by the $r h l B$ gene which leads to the formation of the mono rhamnolipid is induced during mid exponential phase of growth, followed by the induction of the $r h l C$ gene product, the rhamnosyl transferase producing the di rhamnolipid, during early stationary phase. However the transcription of both genes is then shut down as the cells enter full stationary phase indicating that prolongation of the fermentation in the presence of excess substrate will not produce further biosurfactant. An alternative approach such as cell immobilisation and continuous flow may prove more useful.

Large-scale production of MELs does not appear to have been attempted yet, although Kitamoto et al. (2001) reported yields of $>100 \mathrm{~g} / \mathrm{l}$ from $P$. antarctica 
grown on vegetable oils. Pseudozyma yeasts are also able to grow and produce MELS on a range of other low cost substrates, some of which can be considered as by-products or wastes, which makes the prospect of commercial production more inviting. Yields at this level indicate that the control of synthesis of MELS in Pseudozyma may mirror the situation in Candida where high yields of commercially viable sophorolipids can be obtained.

\section{New applications}

Much of the industrial interest in biosurfactants has until now been directed at the bulk product markets, such as laundry detergents and domestic cleaning products. There are, however, many other applications where chemical surfactants are currently used and where some of the special properties of biosurfactants might be usefully employed. One such application is in relation to the formation and disruption of bacterial biofilms (Rodrigues et al. 2007) and other general medically-related applications (Rodrigues et al. 2006). The production of biosurfactants by bacteria has been linked with a number of different functions including motility, adhesion substrate utilisation and biofilm formation (Van Hamme et al. 2006; Fracchia et al. 2012). The role of rhamnolipids in the maintenance of biofilm structure is based on a dynamic disruption of the continuous structure, allowing diffusion of nutrients and gases to the cells within the biofilm. This suggests that biosurfactants might have a useful application in preventing the formation of biofilms on surfaces such as catheters or might be used to disrupt established biofilms on surfaces through their use in surface cleaning formulations (Dusane et al. 2010). Domestic surface-cleaning products already contain chemical surfactants which are not specifically effective at disrupting biofilms and their replacement with biosurfactants offers an exciting new application. The move to produce laundry detergents which can be used in washing machines at low wash temperatures has created a new biofilm situation in the waste pipes where previously high water temperatures inhibited biofilm formation. The presence of biosurfactants in the laundry detergent formulations may also help to overcome this problem.

A relatively new area of application for biosurfactants has appeared with the suggestion that biosurfactants may aid wound healing (Piljac et al. 2008). Once again this opens the possibility that biosurfactants could usefully be incorporated into a wide range of skin care products in place of chemical surfactants and that this would have the added benefit of aiding the healing of minor skin lesions.

One final area where large scale replacement of chemical surfactants could take place is in the environmental remediation field. The fact that biosurfactants are readily biodegradable would be particularly attractive where large quantities of these chemicals are used in, for example, oil spill remediation exercises. There would also be an added benefit on top of the simple oil dispersion and emulsification process since biosurfactant production by bacteria forms a mechanism to enhance access to oil substrates for their growth (Perfumo et al. 2010). Enhanced biodegradation in situ would be of considerable benefit in accelerating the bioremediation process and in turn reducing the overall cost of the environmental damage caused (Franzetti et al. 2011).

\section{Conclusions}

Several of the glycolipid biosurfactants produced by microorganisms offer exciting prospects for future sustainability of large scale commercial products. Progress is currently being made in solving some of the remaining problems associated with biosurfactant use i.e. yield, cost, downstream processing and tailoring of biosurfactant molecules to fulfill specific roles in product formulations. Products are already on the market containing biosurfactants and we can expect to see further exploitation in the near future.

\section{References}

Arutchelvi JI, Bhaduri S, Uppara PV, Doble M (2008) Mannosylerythritol lipids: a review. J Ind Microbiol Biotechnol 35:1559-1570

Banat IM, Franzetti A, Gandolfi I, Bestetti G, Martinotti MG, Fracchia L, Smyth TJ, Marchant R (2010) Microbial biosurfactants production, applications and future potential. Appl Microbiol Biotechnol 87:427-444

Caiazza NC, Shanks RMQ, O'Toole GA (2005) Rhamnolipids modulate swarming motility patterns of Pseudomonas aeruginosa. J Bacteriol 187:7351-7361

Casas JA, Garcia-Ochoa F (1999) Sophorolipid production by Candida bombicola: medium composition and culture methods. J Biosci Bioeng 88:488-494 
Chen ML, Penfold J, Thomas RK, Smyth TJP, Perfumo A, Marchant R, Banat IM, Stevenson P, Parry A, Tucker I, Grillo I (2010a) Mixing behavior of the biosurfactant, rhamnolipid, with a conventional anionic surfactant, sodium dodecyl benzene sulfonate. Langmuir 26:17958-17968

Chen ML, Penfold J, Thomas RK, Smyth TJP, Perfumo A, Marchant R, Banat IM, Stevenson P, Parry A, Tucker I, Grillo I (2010b) Solution self-assembly and adsorption at the air-water interface of the monorhamnose and dirhamnose rhamnolipids and their mixtures. Langmuir 26: 18281-18292

Chen ML, Dong CC, Penfold J, Thomas RK, Smyth TJP, Perfumo A, Marchant R, Banat IM, Stevenson P, Parry A, Tucker I, Campbell RA (2011) Adsorption of sophorolipid biosurfactants on their own and mixed with sodium dodecyl benzene sulfonate at the air/water interface. Langmuir 27:854-8866

Davila AM, Marchal R, Vandecasteele JP (1997) Sophorose lipid fermentation with differentiated substrate supply for growth and production phases. Appl Microbiol Biotechnol 47:496-501

Desai JD, Banat IM (1997) Microbial production of surfactants and their commercial potential. Microbiol Mol Biol Rev 61:47-64

Dubeau D, Déziel E, Woods DE, Lépine F (2009) Burkholderia thailandensis harbors two identical rhl gene clusters responsible for the biosynthesis of rhamnolipids. BMC Microbiol 9:263-274

Dusane DH, Nancharaiah YV, Zinjarde SS, Venugopalan VP (2010) Rhamnolipid mediated disruption of marine Bacillus pumilus biofilms. Colloids Surf Biointerfaces 81:242-248

Fracchia L, Cavallo M, Martinotti MG, Banat IM (2012) Biosurfactants and bioemulsifiers biomedical and related applications-present status and future potentials, biomedical science, engineering and technology, Chap. 14, pp 325-370; Dhanjoo N. Ghista (Eds), ISBN: 978-953307-471-9, InTech

Franzetti A, Gandolfi I, Bestetti G, Banat IM (2011) Biosurfactant and bioremediation, successes and failures. In: Plaza G (ed) Trends in bioremediation and phytoremediation. Research Signpost, Kerala, pp 145-156

Fukuoka T, Morita T, Konishi M, Imura T, Sakai H, Kitamoto D (2007) Structural characterisation and surface-active properties of a new glycolipid biosurfactant, mono-acylated mannosylerythritol lipid, produced from glucose by Pseudozyma antarctica. Appl Microbiol Biotechnol 76:801-810

Fukuoka T, Yanagihara T, Imura T, Morita T, Sakai H, Abe M, Kitamoto D (2011) Enzymatic synthesis of a novel glycolipid biosurfactant, mannosylerythritol lipid-D and its aqueous phase behavior. Carbohydr Res 346:266-271

Guilmanov V, Ballistreri A, Impallomeni G, Gross RA (2002) Oxygen transfer rate and sophorose lipid production by Candida bombicola. Biotechnol Bioeng 77:489-494

Gunther IVNW, Nunez A, Fett W, Solaiman DK (2005) Production of rhamnolipids by Pseudomonas chlororaphis, a nonpathogenic bacterium. Appl Environ Microbiol 71: 2288-2293

Haussler S, Nimtz M, Domke T, Wray V, Steinmetz I (1998) Purification and characterisation of a cytotoxic exolipid of Burkholderia pseudomallei. Infect Immun 66:1588-1593
Hewald S, Linne U, Scherer M, Marahiel MA, Kämper J, Bölker M (2006) Identification of a gene cluster for biosynthesis of mannosylerythritol lipids in the basidiomycetous fungus Ustilago maydis. Appl Environ Microbiol 72:5469-5477

Kitamoto D, Ikegami T, Suzuki T, Sasaki A, Takeyama Y, Idemoto Y, Koura N, Yanagishita H (2001) Microbial conversion of $n$-alkanes into glycolipid biosurfactants, mannosylerythritol lipids by Pseudozyma antarctica. Biotechnol Lett 23:1709-1714

Klekner V, Kosaric N, Zhou QH (1991) Sophorose lipids produced from sucrose. Biotechnol Lett 13:345-348

Lang S, Wullbrandt D (1999) Rhamnose lipids—biosynthesis, microbial production and application potential. Appl Microbiol Biotechnol 51:22-32

Makkar RS, Cameotra SS, Banat IM (2011) Advances in utilization of renewable substrates for biosurfactant production. AMB Express 1:5

Mata-Sandoval JC, Karns J, Torrents A (2001) Effect of nutritional and environmental conditions on the production and composition of rhamnolipids by $P$. aeruginosa UG2. Microbiol Res 155:249-256

Myers D (2006) Surfactant science and technology, 3rd edn. Wiley-Interscience, New York

Ochsner U, Fiechter A, Reiser J (1994) Isolation, characterisation and expression in Escherichia coli of the Pseudomonas aeruginosa rhlAB genes encoding a rhamnosyltransferase involved in rhamnolipid biosurfactant synthesis. J Biol Chem 269:19787-19795

Penfold J, Chen ML, Thomas RK, Dong CC, Smyth TJP, Perfumo A, Marchant R, Banat IM, Stevenson P, Parry A, Tucker I, Grillo I (2011) Solution self-assembly of the sophorolipid biosurfactant and its mixture with anionic surfactant sodium dodecyl benzene sulfonate. Langmuir 27:8867-8877

Perfumo A, Banat IM, Canganella F, Marchant R (2006) Rhamnolipid production by a novel thermotolerant hydrocarbon-degrading Pseudomonas aeruginosa AP02-1. Appl Microbiol Biotechnol 72:132-138

Perfumo A, Smyth T, Marchant R, Banat IM (2010) Production and roles of biosurfactants and bioemulsifiers in accessing hydrophobic substrates. In: Timmis KN (ed) Handbook of hydrocarbon and lipid microbiology. Springer, Berlin, pp 1501-1512

Piljac A, Stipcevic T, Piljac-Zegarac J, Piljac G (2008) Successful treatment of chronic decubitus ulcer with $0.1 \%$ dirhamnolipid ointment. J Cutan Med Surg 12:142-146

Rodrigues L, Banat IM, Teixeira J, Oliveira R (2006) Biosurfactants: potential applications in medicine. J Antimicrob Chemother 57:609-618

Rodrigues L, Banat IM, Teixeira J, Oliveira R (2007) Strategies for the prevention of microbial biofilm formation on silicone rubber voice prostheses. J Biomed Mater Res 81B(2): 358-370

Ron EZ, Rosenberg E (2001) Natural roles of biosurfactants. Environ Microbiol 3:229-236

Saerens KMJ, Zhang JX, Saey L, Van Bogaert INA, Soetaert W (2011) Cloning and functional characterization of the UDP-glucosyltransferase UgtB1 involved in sophorolipid production by Candida bombicola and creation of a glucolipid-producing yeast strain. Yeast 28:279-292 
Smyth T, Perfumo A, Marchant R, Banat I (2010a) Directed microbial biosynthesis of deuterated biosurfactants and potential future application to other bioactive molecules. Appl Microbiol Biotechnol 87:1347-1354

Smyth T, Perfumo A, Marchant R, Banat I (2010b) Isolation and analysis of low molecular weight microbial glycolipids. In: Timmis KN (ed) Handbook of hydrocarbon and lipid microbiology. Springer, Berlin, pp 3705-3723

Smyth TJP, Perfumo A, McClean S, Marchant R, Banat IM (2010c) Isolation and analysis of lipopeptides and high molecular weight biosurfactants. In: Timmis KN (ed) Handbook of hydrocarbon and lipid microbiology. Springer, Berlin, pp 3689-3704

Soberón-Chávez G, Lépine F, Déziel E (2005) Production of rhamnolipids by Pseudomonas aeruginosa. Appl Microbiol Biotechnol 68:718-725

Stoimenova E, Vasileva-Tonkova E, Sotirova A, Galabova D, Lalchev Z (2009) Evaluation of different carbon sources for growth and biosurfactant production by Pseudomonas fluorescens isolated from wastewaters. Z Naturforsch 64:96-102

Van Bogaert INA, Saerens K, De Muynck C, Develter D, Soetaert W, Vandamme EJ (2007) Microbial production and application of sophorolipids. Appl Microbiol Biotechnol 76:23-34
Van Bogaert INA, Sabirova J, Develter D, Soetaert W, Vandamme EJ (2009) Knocking out the MFE-2 gene of Candida bombicola leads to improved medium-chain sophorolipid production. FEMS Yeast Res 9:610-617

Van Bogaert INA, Fleurackers S, Van Kerrebroeck S, Develter D, Soetaert W (2011) Production of new-to-nature sophorolipids by cultivating the yeast Candida bombicola on unconventional hydrophobic substrates. Biotechnol Bioeng 108:734-741

Van Hamme JD, Singh A, Ward OP (2006) Physiological aspects, Part 1 in a series of papers devoted to surfactants in microbiology and biotechnology. Biotechnol Adv 24: $604-620$

Vasileva-Tonkova E, Galabova D, Stoimenova E, Lalchev Z (2006) Production and properties of biosurfactants from a newly isolated Pseudomonas fluorescens HW-6 growing on hexadecane. Z Naturforsch 61:553-559

Zhu K, Rock CO (2008) RhlA converts $\beta$-hydroxyacyl-acyl carrier protein intermediates in fatty acid synthesis to the $\beta$-hydroxydecanoyl- $\beta$-hydroxydecanoate component of rhamnolipids in Pseudomonas aeruginosa. J Bacteriol 190:3147-3154 